\title{
Is quality of YouTube content on Bankart lesion and its surgical treatment adequate?
}

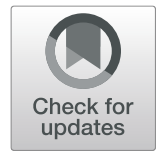

\author{
Ahmet Onur Akpolat ${ }^{*}$ (ID and Demet Pepele Kurdal
}

\begin{abstract}
Background: The Internet has developed into a fast and easy to access source of information. The second most popular social media network is YouTube. We aimed to evaluate the accuracy and quality of videos uploaded to YouTube about Bankart lesion without diagnostic or treatment-related criteria.

Methods: Various keywords were searched for on YouTube. Videos were evaluated with the DISCERN and JAMA Benchmark scoring systems by two independent reviewers.

Results: A total of 48 videos were taken into evaluation as a result of the search. The mean view count was $28909.68 \pm 30264.3$. Mean length of the videos was 313,06 \pm 344.65 . The average DISCERN score of both reviewers was $2.35 \pm 0.91$. The average JAMA Benchmark score of both reviewers was $2.11 \pm 0.77$.

Conclusion: We concluded that the accuracy and reliability of the videos obtained from YouTube by searching for the words Bankart and labrum lesion/injury/treatment are low.
\end{abstract}

Keywords: YouTube, Surgical, Treatment, Quality, Bankart

\section{Introduction}

The Internet has developed into a fast and easily accessible source of information [1]. It is estimated that total Internet use between the years 2000 and 2017 has increased by $962.6 \%$ and that $51 \%$ of the world population has access to the Internet [2]. Rate of social media use between ages $18-29$ is about $90 \%$ [1-3]. Nowadays, the second most commonly used social media network is YouTube, a global social network translated into 76 different languages, used in 88 countries, with over one billion users [4]. YouTube has become an incredible rapid-growing visual database with over 300 video uploads per minute and more than 100 million hours of video views per day [4]. In 2014, according to a study conducted in the USA, YouTube use was $80 \%$ between ages 14 and 29 and $90 \%$ between ages 18 and $49[3,4]$.

Although the main purpose of YouTube is entertainment rather than educational purposes, over time, due to patient interest, it has also become a platform for medical information for academicians and colleagues as

\footnotetext{
* Correspondence: onurakpolat@hotmail.com

Department of Orthopaedics and Traumatology, Fatih Sultan Mehmet

Training and Research Hospital, Istanbul, Turkey
}

well as communication with patients. Videos uploaded to YouTube do not pass an editorial process and most do not contain information on authorship or origin. Users are unfamiliar with the accuracy or reliability of the resource. They may also be subject to misleading advertisements.

When we searched for the word "YouTube" on PubMed (March 10, 2019), we encountered close to a thousand results. A majority of the studies were evaluations of the quality of the content obtained from YouTube. This large number of studies suggest that the quality of information obtained from YouTube is controversial [5]. The Internet is also widely used by orthopedic patients to learn information about their disorders [6].

The Bankart lesion is a lesion of the anterior glenoid labrum of the shoulder [7] and is most commonly caused by recurrent dislocation of the shoulder, with an incidence of $1.7 \%$. Bankart lesion is found in $80 \%$ of patients with recurrent dislocation of the shoulder [7, 8] and is most common between 18 and 30 years of age [8].

Our study's objective was to determine the quality of YouTube videos related to the diagnosis and treatment 
of patients with Bankart lesion, which is most commonly observed in the young population.

\section{Material and methods}

On March 5, 2019, a search containing various keywords was conducted on YouTube (http://www.youtube.com) including "Bankart," "Bankart lesion," "Bankart surgery," and "Bankart Repair," along with "Labrum," "Labrum tear," "Labrum repair," and "Labrum surgery" due to the fact that patients could easily access their magnetic resonance reports.

Studies have shown that less than $17 \%$ of Internet users view results beyond the first three pages of the search results [9]. Therefore, in our study, we only evaluated the first three pages of the results. The other exclusion criteria included repeated videos, non-English videos, inhumane videos, videos that included advertising content, and videos that were viewed less than 10,000 times (Fig. 1). Videos were divided into groups based on criteria such as type (animation, surgical, cadaver, etc.) and upload year, then evaluated using two different scoring systems (DISCERN, JAMA Benchmark).

DISCERN is a scoring system developed at Oxford and used to evaluate the quality of health care. It is originally made up of 16 questions. A score of 1 to 5 is given for each question. The lower score limit is 6 and the upper score is 80 [10]. Singh et al. modified DISCERN for the evaluation of YouTube. Scoring for clarity, reliability, bias/balance, providing of additional information, and uncertainty criteria were established. A score between 0 and 5 is given for each set of criteria. A higher score represents higher video quality [11].

The JAMA Benchmark evaluates the quality of information obtained from the Internet with four criteria. A score is given for each criterion: Internet uploaders (who or by whom they are made, uploaded, and the credentials of such persons), source (explicitly declaring the copyrights of the references and resources contained in the content), explanation (any sponsorship, advertising, commitment, commercial financing of the website), and validation (including comments and updated dates) [12]. The scores are between 0 and 4 , in which a higher score indicates higher video quality.

\section{Statistical evaluation}

Results obtained from the study were statistically analyzed using the IBM SPSS Statistics 22 (IBM SPSS, Turkey) program. When study data was evaluated, the Shapiro-Wilk test was used to assess the relevance of normal distribution of the parameters. Aside from descriptive statistical methods (mean, standard deviation, frequency), in the assessment of quantitative data, the Kruskal-Wallis test was used to compare parameters with and without normal distribution. For the assessment of DISCERN and JAMA Benchmark scores, intraclass correlation (ICC) was calculated to determine the consistency between the reviewers. $P>0.05$ was considered significant.

\section{Results}

The YouTube search yielded 1,864,743 results. After applying exclusion criteria, 48 videos were taken for

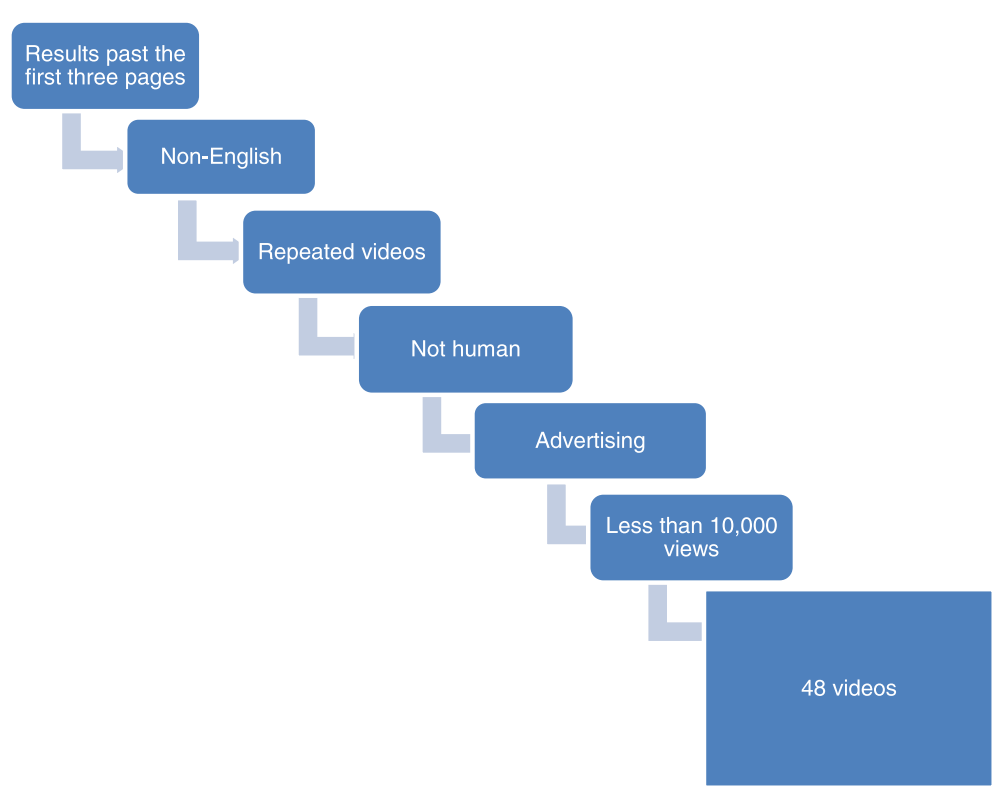

Fig. 1 Exclusion criteria 
evaluation. According to the parametric assessment of the videos, the number of views was between 10,585 and 306,958 and was a mean of $60,604.12 \pm 78,366.9$. The length of the videos was between 4 and $3363 \mathrm{~s}$ and was a mean of $424.43 \pm 566.68$ (Table 1). There were 6 videos from 1 clinic, and 3 videos each from 4 different clinics.

The year with the highest number of uploads was 2010 with an upload rate of $16.66 \%$, while the least number of videos were uploaded in 2017 with an upload rate of $2.08 \%$. Of the evaluated videos, $32(66.66 \%)$ were surgical, 13 (27.08\%) were animations, and 3 (6.25\%) were cadaver videos. Four of the 5 most viewed videos were animations, and 1 was a surgical video. There were 6 videos from 1 clinic, and 3 videos each from 4 different clinics.

\section{Modified DISCERN}

The average DISCERN score by reviewer 1 was $2.35 \pm$ 0.98 . The average DISCERN score by reviewer 2 was $2.35 \pm 0.95$. The average score of both reviewers was $2.35 \pm 0.91$ (Table 1). The consistency of the DISCERN score between both reviewers was $78.6 \%$, which was statistically significant $(p=0.000 ; p<0.05)$ (Table 2$)$.

\section{JAMA Benchmark}

The average JAMA Benchmark score by reviewer 1 was $2.1 \pm 0.79$. The average JAMA Benchmark score by reviewer 2 was $2.13 \pm 0.76$. The average score of both reviewers was $2.11 \pm 0.77$ (Table 1). The consistency of the JAMA Benchmark scores of both reviewers was $97.3 \%$, which was statistically significant $(p=0.000$; $p<0.05)$ (Table 3).

Table 1 Evaluation of the study parameters

\begin{tabular}{llll}
\hline & & Min-max & Mean \pm SD \\
\hline Number of views & & $10,585-306,958$ & $60,604.12 \pm 78,366.9$ \\
Length (s) & & $14-3363$ & $424.43 \pm 566.68$ \\
Upload year & 2007 & 3 & 6.25 \\
& 2008 & 5 & 10.41 \\
& 2009 & 5 & 10.41 \\
& 2010 & 8 & 16.66 \\
& 2011 & 4 & 8.33 \\
& 2012 & 7 & 14.58 \\
& 2013 & 6 & 12.5 \\
& 2014 & 3 & 6.25 \\
& 2015 & 3 & 6.25 \\
& 2016 & 3 & 6.25 \\
& 2017 & 1 & 2.08 \\
& Animation & 13 & 27.08 \\
& Surgical & 32 & 66.6 \\
& Cadaver & 3 & 6.25 \\
\hline
\end{tabular}

Table 2 Evaluation of JAMA Benchmark and DISCERN scoring

\begin{tabular}{lll}
\hline & Min-Max & Mean \pm SD \\
\hline DISCERN reviewer 1 & $1-4$ & $2.35 \pm 0.98$ \\
DISCERN reviewer 2 & $1-4$ & $2.35 \pm 0.95$ \\
JAMA reviewer 1 & $1-3$ & $2.1 \pm 0.79$ \\
JAMA reviewer 2 & $1-3$ & $2.13 \pm 0.76$ \\
DISCERN score & $1-4$ & $2.35 \pm 0.91$ \\
JAMA score & $1-3$ & $2.11 \pm 0.77$ \\
\hline
\end{tabular}

There was no statistically significant difference in DISCERN or JAMA Benchmark scores according to video type $(p>0.05)$ (Table 4$)$

\section{Discussion}

The main reason we presented this hypothesis in our study was the significant increase in the number of patients who had searched the Internet and applied to our outpatient clinic. Image search is a common type of search method. YouTube is a social network of high interest due to its ease of access to information [13]. Healthy sources of information on the Internet may increase patient satisfaction and compliance with treatment $[14,15]$. However, the accuracy and quality of the information obtained by patients cannot be evaluated.

In our study, we found that the videos obtained from a YouTube search containing the words "Bankart lesion/ injury/treatment" and "Labrum tear/repair/surgery" were of poor quality. It is known that low quality medical information obtained from YouTube has a negative effect on doctor-patient relationship [16].

When we scanned the literature, we encountered a large number of publications on evaluating video quality of different branches and diseases and all of them concluded that the accuracy of the information and quality of the videos were poor. The results of our study were consistent with the results of those studies [17-25].

Four of the top five most viewed videos were animations. The studies we encountered in the literature also had high view rates for animated videos [25]. They attributed this to the fact that animated videos were visually simple and easy to understand [22].

The most common video type was surgical videos, but had the lowest view rate, similar to other studies. Previous studies suggested that this lower view rate was due to the content being too complex for viewers

Table 3 Consistency levels between DISCERN and JAMA Benchmark scores of the reviewers

\begin{tabular}{lclll}
\hline & ICC & $95 \% \mathrm{Cl}$ & & $p$ \\
\hline DISCERN & 0.786 & 0.603 & 0.891 & $0.000^{*}$ \\
JAMA Benchmark & 0.973 & 0.945 & 0.987 & $0.000^{*}$ \\
\hline $\begin{array}{l}\text { ICC intraclass correlation coefficient } \\
{ }^{*} p<0.05\end{array}$ & & &
\end{tabular}


Table 4 Evaluation of DISCERN and JAMA Benchmark scores according to video type

\begin{tabular}{|c|c|c|}
\hline \multirow{2}{*}{$\begin{array}{l}\text { Video } \\
\text { type }\end{array}$} & DISCERN & JAMA Benchmark \\
\hline & Mean \pm SS (median) & Mean \pm SS (median) \\
\hline Animation & $2.64 \pm 0.69(2.5)$ & $2 \pm 0.58(2)$ \\
\hline Surgical & $2.38 \pm 0.95(2.5)$ & $2.19 \pm 0.81$ \\
\hline Cadaver & $1.5 \pm 0.87(1)$ & $1.83 \pm 1.04(1.5)$ \\
\hline$p$ & 0.241 & 0.645 \\
\hline
\end{tabular}

Kruskal-Wallis test

without medical education and were visually unappealing $[25,26]$.

Many of the videos were from the same or similar clinics. According to the literature, the mutual opinion was that the surgeon's desire to raise awareness of themselves and their clinics was the main cause of this situation [25-27].

Although both tests used in the study have been widely used in many publications and tested for reliability, we reevaluated the consistency of both tests within the groups. Obtained data showed high intra-group compliance [25-28].

We found that video quality was poor regardless of video type. Studies in the literature have yielded similar results [25-29].

There are various studies in the literature on orthopedic disorders and their surgical treatments, including distal radius fracture [20], carpal tunnel syndrome [21], pediatric orthopedics [19], cervical disk herniation [22], spinal stenosis treatment [29], and knee arthroscopy and injuries [18]. In these studies, popular search engines (Google/Yahoo/Yandex) were investigated instead of YouTube. In conclusion, it was found that information acquired from the Internet was insufficient and sometimes inaccurate [19-22, 25, 29]. Another study reported that significant correlations were observed between the video's usefulness and the uploaded source, as well as between the video's usefulness and viewers' preferences, such as the number of views, views per day, and number of likes [30].

There are limited orthopedic studies that evaluate the accuracy and quality of YouTube content. Staunton et al. evaluated results of a YouTube search regarding scoliosis using JAMA Benchmark scoring and found that the information was of poor quality [26]. JAMA Benchmark and DISCERN scoring were also used in studies on femoroacetabular impingement syndrome [27], hip arthritis [28], and anterior cruciate ligament (ACL) injury and reconstruction [25], as in our study. The results of the aforementioned studies were similar to ours, in that the information acquired from YouTube was of insufficient-low quality.
Some studies state that the information accessed from YouTube is insufficient and that doctors should present an alternative to prevent patients from misinformation [12]. YouTube videos could be used as learning sources for shoulder physical examinations after the application of appropriate filtering processes, such as review of the upload source and viewers' preferences [30].

Our study had some limitations. These were as follows: the search and results were momentary, and factors such as YouTube's coding system, the search history of the IP address of the computer, and localization having an unknown effect on the search results.

\section{Conclusions}

Medicine is a field, due to its nature, in constant communication with people, regardless of branch. We believe that the quality of information obtained from a platform that we have no intervention over is significant. It should not be forgotten that providing patients with an accurate, quality flow of information will reduce the need for an additional need of information during treatment. However, no matter what, it may be difficult to suppress the curiosity and need to research due to human nature.

\section{Acknowledgements}

Not applicable.

\section{Authors' contributions}

AOA conceived and designed the study. AOA and DPK contributed to the data collection. AOA and DPK analyzed the data. AOA and DPK wrote the manuscript. All authors read and approved the final manuscript and consented to publish this manuscript.

\section{Funding}

The author(s) received no financial support for the research,authorship, and/ or publication of this article.

\section{Availability of data and materials}

The datasets generated and/or analyzed during the current study are available from the corresponding author on reasonable request

Ethics approval and consent to participate

This retrospective study was approved and consented by the Ethics Committee of Fatih Sultan Mehmet Training and Research Hospital.

Consent for publication

Not applicable

\section{Competing interests}

The authors declare that they have no competing interests.

Received: 18 September 2019 Accepted: 30 October 2019

Published online: 26 February 2020

\section{References}

1. Pew Research Centre (2015) Social Media Usage: 2005-2015. http:/ www. pewinternet.org/2015/10/08/social-networking usage 2005-2015/. Accessed 7 May 2016

2. http://www.internetworldstats.com/stats.htm, Internet users in June 30, 2017 
3. Pew Research Centre (2015) 5 facts about online video, for YouTube's 10th birthday.

4. YouTube statistics. https:/www.youtube.com/yt/press/statistics.html

5. O'Neill SC, Baker JF, Fitzgerald C, Fleming C, Rowan F, Byrne D, Synnott K. Cauda equina syndrome: assessing the readability and quality of patient information on the Internet. Spine (Phila Pa 1976). 2014;39(10):E645-9.

6. Cassidy JT, Baker JF. Orthopaedic patient information on the World Wide Web: an essential review. J Bone Joint Surg Am. 2016;98(4):325-38.

7. Widjaja AB, Tran A, Bailey M, Proper S. Correlation between Bankart and HillSachs lesions in anterior shoulder dislocation. ANZ J Surg. 2006;76(6):436-8.

8. Buss DD, Lynch GP, Meyer CP, Huber SM, Freehill MQ. Nonoperative management for in-season athletes with anterior shoulder instability. Am J Sports Med. 2004;32(6):1430-3.

9. Jansen B, Spink A. An analysis of web documents retrieved and viewed. In: The 9th International Conference on Internet Computing. Las Vegas; 2003. https://faculty.ist.psu.edu/jjans.

10. Charnock D, Shepperd S, Needham G, Gann R. DISCERN: an instrument for judging the quality of written consumer health information on treatment choices. J Epidemiol Community Health. 1999;53(2):105-11.

11. Singh AG, Singh S, Singh PP. YouTube for information on rheumatoid arthritis--a wakeup call? J Rheumatol. 2012;39(5):899-903.

12. Silberg WM, Lundberg GD, Musacchıo RA. Assessing, controlling, and assuring the quality of medical information on the Internet: caveant lector et viewor-let the reader and viewer beware. JAMA. 1997;277(15):1244-5.

13. Desai T, Shariff A, Dhingra V, Minhas D, Eure M, Kats M. Is content really king? An objective analysis of the public's response to medical videos on YouTube. PLoS One. 2013:8(12):e82469.

14. Hungerford DS. Internet access produces misinformed patients: managing the confusion. Orthopedics. 2009;32:9.

15. Sechrest RC. The internet and the physician-patient relationship. Clin Orthop Relat Res. 2010;468(10):2566-71.

16. Madathil KC, Rivera-Rodriguez AJ, Greenstein JS, Gramopadhye AK. Healthcare information on YouTube: a systematic review. Health Informatics J. 2015;21(3):173-94

17. Duncan IC, Kane PW, Lawson KA, Cohen SB, Ciccotti MG, Dodson CC. Evaluation of information available on the Internet regarding anterior cruciate ligament reconstruction. Arthroscopy. 2013;29(6):1101-7.

18. Bruce-Brand RA, Baker JF, Byrne DP, Hogan NA, McCarthy T. Assessment of the quality and content of information on anterior cruciate ligament reconstruction on the internet. Arthroscopy. 2013;29(6):1095-100.

19. Winship B, Grisell M, Yang CB, Chen RX, Bauer AS. The quality of pediatric orthopaedic information on the internet. J Pediatr Orthop. 2014;34(4):474-7.

20. Dy CJ, Taylor SA, Patel RM, Kitay A, Roberts TR, Daluiski A. The effect of search term on the quality and accuracy of online information regarding distal radius fractures. J Hand Surg Am. 2012;37(9):1881-7.

21. Beredjiklian PK, Bozentka DJ, Steinberg DR, Bernstein J. Evaluating the source and content of orthopaedic information on the Internet. The case of carpal tunnel syndrome. J Bone Joint Surg Am. 2000;82(11):1540-3.

22. Morr S, Shanti N, Carrer A, Kubeck J, Gerling MC. Quality of information concerning cervical disc herniation on the Internet. Spine J. 2010;10(4):350-4.

23. Sambandam SN, Ramasamy V, Priyanka P, llango B. Quality analysis of patient information about knee arthroscopy on the World Wide Web. Arthroscopy. 2007;23(5):509-513.e2.

24. Starman JS, Gettys FK, Capo JA, Fleischli JE, Norton HJ, Karunakar MA. Quality and content of Internet-based information for ten common orthopaedic sports medicine diagnoses. J Bone Joint Surg Am. 2010;92(7):1612-8

25. Cassidy JT, Fitzgerald E, Cassidy ES, Cleary M, Byrne DP, Devitt BM, Baker JF. YouTube provides poor information regarding anterior cruciate ligament injury and reconstruction. Knee Surg Sports Traumatol Arthrosc. 2018;26(3):840-5.

26. Staunton PF, Baker JF, Green J, Devitt A. Online curves: a quality analysis of scoliosis videos on YouTube. Spine (Phila Pa 1976). 2015;40(23):1857-61.

27. MacLeod MG, Hoppe DJ, Simunovic N, Bhandari M, Philippon MJ, Ayeni OR. YouTube as an information source for femoroacetabular impingement: a systematic review of video content. Arthroscopy. 2015;31 (1):136-42.

28. Fischer J, Geurts J, Valderrabano V, Hügle T. Educational quality of YouTube videos on knee arthrocentesis. J Clin Rheumatol. 2013;19(7):373-6.

29. Nason K, Donnelly A, Duncan HF. YouTube as a patient-information source for root canal treatment. Int Endod J. 2016;49(12):1194-200.
30. Lee H, Choi A, Jang Y, Lee Jl. YouTube as a learning tool for four shoulder tests. Prim Health Care Res Dev. 2018;30:1-7.

\section{Publisher's Note}

Springer Nature remains neutral with regard to jurisdictional claims in published maps and institutional affiliations.

\section{Ready to submit your research? Choose BMC and benefit from:}

- fast, convenient online submission

- thorough peer review by experienced researchers in your field

- rapid publication on acceptance

- support for research data, including large and complex data types

- gold Open Access which fosters wider collaboration and increased citations

- maximum visibility for your research: over $100 \mathrm{M}$ website views per year

At BMC, research is always in progress.

Learn more biomedcentral.com/submissions 